\title{
Flocculation and retention of fillers with nanocelluloses
}

\section{Markus H.J. Korhonen, Janne Laine}

KEYWORDS: Nanofibrillar cellulose, Flocculation, Charge density, Filler, retention

SUMMARY: The objective of this study was to examine the effect of different cellulose nanofibrils (CNF) on the flocculation and retention of precipitated calcium carbonate (PCC) and kaolin. Of particular interest was the study of how charge modifications of CNF affect its flocculation and retention capacity. The results clearly show that different CNFs can be used as flocculants and retention aids. However, CNFs have to be chemically modified (high charge density) in order to increase their electrostatic interactions with particles and other additives, and hence boost flocculation. Furthermore, the flocculation and retention efficiency is significantly improved when charge modified CNFs are combined with polyelectrolytes. It is probable that the presence of polyelectrolytes can strengthen and induce formation of $\mathrm{CNF} /$ polyelectrolyte bridges between filler particles, leading to efficient flocculation. Charge modified CNF could be used to increase filler retention up to $95 \%$ in both one and two component systems. The maximum retention was strongly dependent on the charge density of $\mathrm{CNF}$ in a two component system and on the polyelectrolyte concentration used.

\begin{tabular}{l}
\hline ADDRESSES OF THE AUTHORS: Markus \\
Korhonen (markus.korhonen@aalto.fi), Janne Laine \\
(janne.laine@aalto.fi) Department of Forest Products \\
Technology, Aalto University, FI-00076 Aalto, Finland \\
Corresponding author: Markus Korhonen
\end{tabular}

Synthetic polyelectrolytes are commonly used in wide variety of industrial applications such as water purification and waste water treatment. In the paper industry they are used for several purposes such as to increase retention of fines and fillers (kaolin, PCC etc.), and hence to improve paper quality and reduce material and energy costs (Roberts 1996). Due to increasing oil price and environmental consciousness renewable natural based materials have gained great interest across the globe. Indeed, the interest in flocculation with several natural carbohydrates and their derivatives such as pectin (Yokoi et al. 2002), dextran (Ghimici, Nichifor 2010, lignin (Fang et al. 2010), and starch (Aly 2006; Chen et al. 2007; Shirzad-Semsar et al. 2007; Wei et al. 2008) has increased significantly in recent years. Cellulose and its derivates have also recently gained interest in flocculation studies. Liimatainen and coworkers (Liimatainen et al. 2011; Sirviö et al. 2011a, 2011b) studied cationically modified cellulose biopolymers, and Biswal and Singh (2004; 2006) grafted carboxymethylated cellulose to be applied as flocculants. In addition, cellulose based nanomaterials have been developed and increasingly studied in past decade. Cellulose nanofibrils (CNF) or cellulose microfibrils (CMF) can be produced by mechanically disintegrating chemical pulps (Pääkkö et al. 2007), in which they preserve their chemical composition and high aspect ratio of cellulose fibrils. A more effective way to fibrillate fibres is to chemically treat the pulp before fibrillation. In this way the properties of the fibrils, such as their size and surface charge can also be modified. However, chemical treatment should not be too harsh to avoid hydrolysis of the amorphous part of cellulose, which would lead to shorter fibrils. One effective method to chemically modify the pulp to produce high charge fibrils is selective oxidation of the primary hydroxyl groups of cellulose into carboxyl groups via 2,2,6,6-tetramethylpiperidine-1-oxyl radical oxidation (TEMPO) (Bragd et al. 2004; Saito et al. 2007). The charged groups prevent the aggregation of fibrils via electrostatic repulsion. Charged groups can also be introduced to the pulp by carboxymethylation using the method described by Walecka (1956) and further developed to produce nanofibrils by Wågberg et al. (2008). Cellulose fibres can also be cationized prior to fibrillation via covalent modification with 2,3 epoxypropyltrimethhylammonium chloride (EPTAC) (Olszewska 2011; Eronen et al. 2012) or by cationizing cellulose via periodate oxidation and hence introducing aldehyde groups on cellulose (Liimatainen et al. 2011; Sirviö et al. 2011a; 2011b).

Due to CNF's and CMF's physical and chemical properties, they can be used in several different industrial applications. These cellulosic materials have already shown promising results in several fields such as composite materials (Hubbe et al. 2008), high strength films (Henriksson et al. 2008), strength addition of paper (Ahola et al. 2008a; Eriksen et al. 2008; Guimond et al. 2010; Taipale et al. 2010), rheology modification (DimicMisic et al. 2013) and flocculation and retention of particles (Suopajärvi et al. 2013; Ämmälä et al. 2013). $\mathrm{CNF}$ and $\mathrm{CMF}$ fibrils have a large specific surface area and high aspect ratio and they form a network already in very dilute aqueous suspensions. Therefore, it is likely that they can also effectively bind, and hence flocculate, small particles such as fines and fillers. The increased surface charge due to chemical modification can also be assumed to affect their flocculation capacity. The aim of this study was to examine the effect of different anionic and cationic CNFs on flocculation/ reflocculation and the retention of precipitated calcium carbonate (PCC) and kaolin. Particular attention was paid to a comparison of the one component CNF system with two component systems, in which CNF was combined with different polyelectrolytes. 


\section{Materials and methods}

\section{Fillers}

Two different fillers, kaolin and PCC, were used in the experiments. The kaolin was Intrafill $\mathrm{C}$ obtained from Imerys International, France. Dried precipitated calcium carbonate (PCC) was provided by Specialty Minerals Inc., USA. Both fillers were dispersed to a dry solids content of 20-30 wt- $\%$ in distilled water without dispersing agents. Mean particle size was ca. $2 \mu \mathrm{m}$ for PCC and ca. $5 \mu \mathrm{m}$ for kaolin (given by the manufacturers).

For the experiments, filler suspensions were diluted to a concentration of $0.1 \mathrm{w}-\%$ in a saline solution of $10 \mathrm{mmol} / \mathrm{l} \mathrm{NaCl}$. The $\mathrm{pH}$ of the suspensions was adjusted with $0.1 \mathrm{M} \mathrm{NaOH}$ to 8.5 for PCC and with $0.1 \mathrm{M} \mathrm{HCl}$ to 5.0 for kaolin. At these conditions PCC was cationic (zeta-potential $15 \mathrm{mV}$ ) and kaolin was anionic (zeta potential $-43 \mathrm{mV}$ ).

\section{Cellulosic materials}

Three anionic and two cationic CNFs were used in the experiments. They were prepared at the Finnish Centre for Nanocellulosic Technologies (Espoo, Finland). The starting material was industrial bleached hardwood kraft pulp. The low charged anionic CNF was fibrillated without chemical modification by using only mechanical shearing (with 4 passes through a high-pressure fluidizer) (Microfluidizer M-110EH, Microfluidics Corp, Newton USA). The two other anionic CNFs were chemically modified before fibrillation (one pass, Microfluidizer); one with the carboxymethylation $(\mathrm{CM})$ process (Walecka 1956; Ahola et al. 2008b; Wågberg et al. 2008) and the other with the TEMPO oxidation process (Bragd et al. 2004; Saito et al. 2007). The two cationic CNFs were prepared by cationizing bleached birch fiber (UPMKymmene Oyj) with commercial Raisacat-reagent (73\% glycidyl trialkylammoniumchloride) with $\mathrm{NaOH}$ and water as the catalysts. The total nitrogen $(\mathrm{g} / \mathrm{kg})$ of washed samples was analyzed by Kjeldahl titration. The degree of substitution was calculated from the total nitrogen results. Cationic fibers were fibrillated by Masuko Supermass Colloider (MKZA10-15J), Japan, (one pass).

For the experiments, CNFs were diluted to a consistency of $0.2 \%$ at $\mathrm{pH} 8$ and with a saline concentration of $10 \mathrm{mmol} / \mathrm{l} \mathrm{NaCl}$. The charges of the CNFs were determined by conductometric titration using the method described by Junka et al. (2013). Charge densities for the CNFs were $-0.065 \mathrm{meq} / \mathrm{g}$ for the unmodified grade and $-0.55 \mathrm{meq} / \mathrm{g}$ and $-1.0 \mathrm{meq} / \mathrm{g}$ for the CM and the TEMPO grades, respectively. For cationic CNFs the charge density (CD) was $0.41 \mathrm{meq} / \mathrm{g}$ for low $\mathrm{CD} C N F$ and $1.37 \mathrm{meq} / \mathrm{g}$ for high $\mathrm{CD} \mathrm{CNF}$.

The bleached thermomechanical pulp (TMP, ${ }^{\circ} \mathrm{SR} 22$ ) used in the retention experiments was delivered from a Finnish pulp mill.

\section{Polyelectrolytes}

One cationic polyacrylamide (CPAM, CD $1.2 \mathrm{meq} / \mathrm{g}$, MW 7 mil. g/mol), one cationic branched polyethyleneimine (PEI, CD $6.1 \mathrm{meq} / \mathrm{g}$, MW $0.1 \mathrm{mil}$. $\mathrm{g} / \mathrm{mol}$ ) and two anionic polyacrylamides (APAM) (-1.6 meq/g, $7 \mathrm{mil} . \mathrm{g} / \mathrm{mol}$ and $-1.3 \mathrm{meq} / \mathrm{g}, 2 \mathrm{mil} . \mathrm{g} / \mathrm{mol})$ were used in the experiments. Cationic (CPAM) and anionic polyacrylamides (APAM) were obtained from Kemira Ltd, Finland, and the polyethyleneimine (PEI) from Sigma-Aldrich St. Louis, MO, USA. The molecular weights (MW) of the polyelectrolytes used were given by the producers and the charge densities (CD) were determined by using polyelectrolyte titration (Koljonen et al. 2004).

\section{Flocculation experiments}

The flocculation of fillers was studied with a Turbiscan Online optical analyzer (Formulaction, France). In this device a near-infrared focused LED (wavelength $850 \mathrm{~nm}$ ) illuminates the scattering medium flowing through a cylindrical glass tube. Both the transmitted (detection angle $0^{\circ}$ ) and the backscattered (detection angle $135^{\circ}$ ) light were measured with the device. The details of the use of this device are presented elsewhere (Bordes et al. 2002).

In order to measure flocculation as a function of time the Turbiscan Online was built into a circulation system that has been used in our previous experiments (Korhonen et al. 2013). $200 \mathrm{ml}$ of filler slurry was continuously pumped from the sample vessel equipped with a magnetic stirrer through the measuring cell with a flow rate of ca. $10 \mathrm{~cm}^{3} / \mathrm{s}$. The sample vessel had a similar geometry as the Dynamic Drainage Jar (Britt, Unbehend 1976). The diameter of the pipe was $5 \mathrm{~mm}$ and total length $75 \mathrm{~cm}$. The transmission and the backscattering values were measured every $0.5 \mathrm{~s}$. In the flocculation tests the stirring speed was kept constant (500 rpm). With the single component systems, CNF and/or a polyelectrolyte was added to the sample slurry and then mixed for an additional 300 seconds. With two component systems, the second component was added $60 \mathrm{~s}$ after the first component and mixing was continued for additional an 240 seconds. Reversibility of flocculation was analyzed by mixing the samples for $60 \mathrm{~s}$ with stirring speed of $500 \mathrm{rpm}$, after that, the stirring speed was altered repeatedly between $1000 \mathrm{rpm}$ and $500 \mathrm{rpm}$ every 60 seconds for a total of 420 seconds. The consistency of the slurry was $0.1 \%$. The salt concentration was $10 \mathrm{mmol} / \mathrm{l} \mathrm{NaCl}$ in both PCC systems $(\mathrm{pH} 8)$ and in kaolin systems (pH 5).

\section{Retention experiments}

The retention of kaolin was studied with a Dynamic Drainage Jar (Britt, Unbehend 1976). The consistency of the furnish was $0.5 \%$ and it was composed of $60 \mathrm{w}-\%$ of TMP pulp and $40 \mathrm{w}-\%$ kaolin. The mixing time (1000 rpm) before dewatering was 60 seconds, and the wire was 100 mesh. As both TMP and kaolin have 
anionic surface charge, the retention of kaolin was studied with two cationic CNFs (high CD and low CD). In addition, a two component system, PEI + TEMPO $\mathrm{CNF}$, was also studied. After the retention experiment, the wire water was filtered with ashless filter paper (Whatman cat.no. 1441110) and the paper was burned in the oven $\left(625^{\circ} \mathrm{C}\right)$ in order to determine the ash content of the wire water. From the ash content, the wire retention of kaolin was determined. The salt concentration was $10 \mathrm{mmol} / \mathrm{l} \mathrm{NaCl}$ and $\mathrm{pH} 5$ in every test point.

\section{Results and discussion}

\section{Flocculation of fillers with different CNFs}

Since PCC has a cationic surface charge, anionic polyelectrolytes (PE) and anionic CNFs adsorb on its surface. This will cause flocculation of PCC particles through either the patch or bridging flocculation mechanisms. Fig 1 shows how PCC particles flocculate after the addition of APAM or CNF (after 60 seconds) as a function of dosage. The flocculation of PCC particles in Fig 1 can be seen as an increase in the transmission level of the PCC suspension. This increase is due to a flocculation of PCC particles into bigger aggregates allows more light from the Turbiscan's light source to pass through the sample to the detector (Bordes et al. 2002). In the flocculation tests the shear condition was kept constant $(500 \mathrm{rpm})$, and it was chosen in a way that the breakage of the flocs was as low as possible.

In the flocculation of PCC, two APAMs with different molecular weights ( 2 and $7 \mathrm{mil} . \mathrm{g} / \mathrm{mol}$ ) were used as a reference for CNFs. The molecular weight of APAM had a significant effect on its flocculation capability. With the high Mw APAM a much higher flocculation level was achieved than with the lower Mw APAM. These types of APAMs flocculate particles mainly through the bridging mechanism, and the $\mathrm{Mw}$ has a significant role in the extension of the polyelectrolytes tails from the surface, hence, affecting its bridging ability (Roberts 1996).

With the High Mw APAM the highest flocculation was achieved with the dosage level of $0.025 \%$. At higher dosages, steric hindrance starts to interfere with the flocculation. The decrease in the flocculation efficiency at high polymer dosages is a well-known effect for flocculants which function through bridging (Swerin et al. 1996).

Three different types of anionic CNFs were tested in the flocculation tests. The flocculation of PCC particles can be enhanced significantly with certain $\mathrm{CNF}$ grades. However, the flocculation efficiency of CNF depends greatly on its properties. The unmodified CNF grade did not increase the transmission level of the PCC suspension at all; indicating that the low charge $\mathrm{CNF}$ did not managed to bridge PCC particles, and hence flocculate them. On the other hand, the chemically modified CNF grades showed substantial flocculation of PCC particles. With the TEMPO CNF, the transmission level increased significantly already at low dosages $(0.05 \%)$. The flocculation maximum with the TEMPO CNF was achieved at $0.5 \%$ of dry weight of PCC. The flocculation efficiency was lower for the CM CNF than for the TEMPO CNF. On the other hand, a slightly higher flocculation maximum was achieved with the CM CNF, optimal dosing being between $0.5-1.0 \%$ of dry weight of PCC. These results indicate that the electrostatic interaction between cationic PCC and anionic CNF is the major driving force for the particle-CNF interaction that leads to flocculation. CNFs are known to have a high aspect ratio and a high surface area and they probably form a nanonetwork already at very dilute aqueous suspensions, as suggested by Salmi et al. (2009). It seems that for the efficient flocculation, a sufficient amount of electrostatic interaction between PCC and CNF is needed. In the unmodified CNFs the charges originate mainly from uronic acid groups bound to hemicelluloses (Sjöström 1993), and therefore the charge density of the unmodified grade was very low $(-0.065 \mathrm{meq} / \mathrm{g})$. Eronen et al. (2012) also found out that these types of CNFs formed curled and interlocked aggregated fibril bundles which might also decrease their flocculation capability. The higher amount of carboxyl groups in chemically modified fibrils increase the electrostatic attraction between the cationic PCC particles and the anionic charge groups of CNF. Thus, there were enough anionic sites on the CNF surface which could attach to adjacent PCC particles and bind them together. In our study the TEMPO CNF had a total charge of $-1.0 \mathrm{meq} / \mathrm{g}$ and carboxymethylated CNF $-0.55 \mathrm{meq} / \mathrm{g}$, which both are significantly higher than that of the unmodified CNF. Another sign of the importance of the electrostatic interaction was that the TEMPO CNF, which had a higher charge than the CM, flocculated PCC more efficiently at low dosage, and also reached optimal flocculation at lower dosages. After maximum flocculation, the electrostatic/ electrosteric repulsion between PCC particles covered with anionic CNF began to decrease the flocculation of PCC. This is typical for polymeric flocculants. Hence, Swerin and coworkers (1996) suggested in their model for bridging flocculants, which was supported by flocculation and retention experiments that the flocculation efficiency starts to decrease when the surface coverage of particles by polymers exceeds $50 \%$.

Another difference between the chemically modified and unmodified CNF is their morphology (Isogai et al. 2011). Because high charge in the chemically modified CNF increases the electrostatic repulsion between the fibrils and during the preparation of CNF, a high amount of individual fibrils is formed instead of fibril bundles (Isogai et al. 2011). It has also been found that chemically modified fibrils exist in a very straight conformation (Eronen et al. 2012) that can improve network flocculation efficiency. Eronen et al. (2012) also found in model surface studies that highly charged chemically 


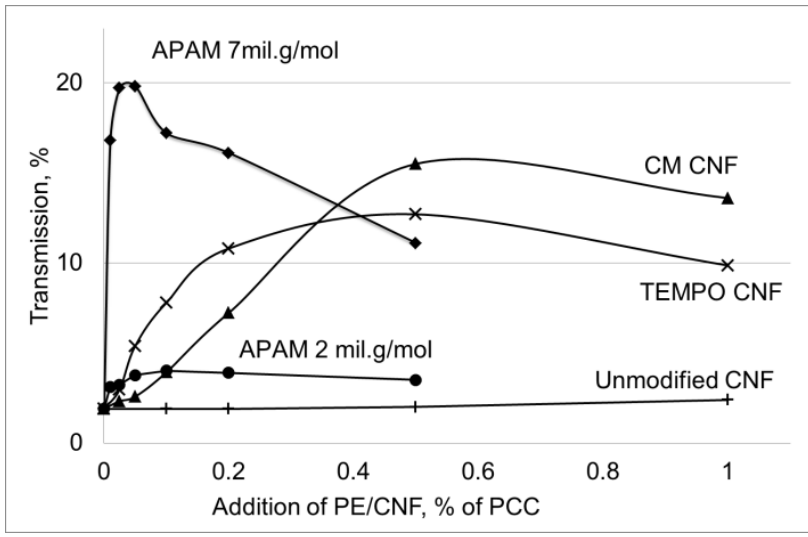

Fig 1 - Effect of the addition of different PEs and CNFs (\% of dry weight of PCC) on the flocculation after $60 \mathrm{~s}$ of PE/CNF addition. The consistency of the PCC suspension was $0.1 \%$.

modified CNFs form very long-range interactions, which should be beneficial for bridging flocculation efficiency. The higher maximum flocculation capacity of CM CNF than that of TEMPO CNF may be due to the length, and hence, networking efficiency of the fibrils. The harsh TEMPO oxidation conditions can weaken cellulose chains that can lead to shortening of TEMPO CNF fibrils in mechanical treatments (Isogai et al. 2011).

When compared with the APAMs, chemically modified CNFs can be considered as moderately effective flocculants. They were significantly more effective than the APAM with a molecular weight of 2 million $\mathrm{g} / \mathrm{mol}$. When compared with the APAM with high molecular weight ( 7 million $\mathrm{g} / \mathrm{mol}$ ), the maximum flocculation level was somewhat lower, but the dosing window was much broader, and thus surface saturation did not seem to deteriorate flocculation as much as with the APAM.

Because the chemically modified CNFs produced significant flocculation, a more detailed analysis of flocculation kinetics was made. Fig $2 a$ and $2 b$ present the flocculation of PCC with the TEMPO and CM CNF as a function of time with different addition levels of the CNFs. With both CNFs, flocculation was fast (it started almost instantly after CNF addition) and the maximum flocculation was achieved from 40 to $70 \mathrm{~s}$ after CNF addition. As the flocculation was fast, it is probable that flocculation occurred mainly through electrostatic interaction. The relatively high transmission shows that the flocculation efficiency is high and the quite broad effective dosing range indicates that bridging/ networking is less sensitive to CNF dosing than that of polymeric flocculants such as APAM. However, dosing of CNFs had an effect on flocculation. With the $0.5 \%$ dose of the TEMPO CNF, the slope of the curve was steepest, meaning that the flocculation rate was the highest. Also the highest flocculation efficiency was achieved at that dose. With the $1.0 \%$ dose we can see that flocculation starts to deteriorate, probably due to the surface saturation of PCC with TEMPO CNF, which leads to repulsion between PCC particles covered with CNF. As mentioned earlier, the decrease in flocculation efficiency at high
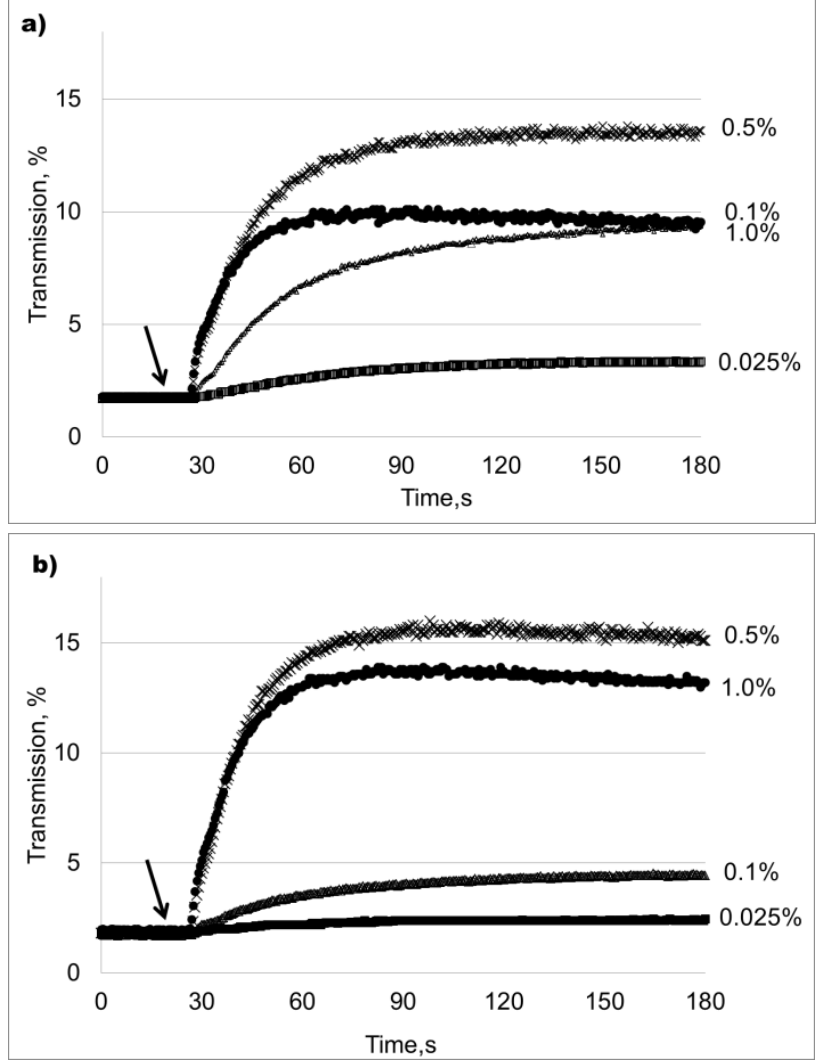

Fig $2 \mathrm{a}$ and $2 \mathrm{~b}$ - Flocculation efficiency of PCC with four addition levels (\% of dry weight of PCC) of TEMPO CNF (a) and CM CNF (b). The dosage start time (20s) is shown by arrow. The consistency of the PCC suspension was $0.1 \%$.

additive dosages is a well-known effect for several types of flocculants (Swerin et al. 1996). The flocculation behavior with the $\mathrm{CM} \mathrm{CNF}$ was rather similar to the TEMPO CNF. The flocculation was lower at smaller dosages but when the dose was increased up to $0.5 \%$ we can see that the flocculation efficiency was very high. We can also conclude that the optimum dosing was higher with $\mathrm{CM} C \mathrm{CNF}$, probably due to the lower surface charge of the CM CNF compared to TEMPO CNF. Thus, larger amounts of CM CNF can be added to the PCC suspension before surface saturation and charge reversal start to deteriorate flocculation. From these results it can be concluded that flocculation with CNFs follows the basic principles of polymeric flocculant theories (Fleer et al. 1993; Swerin et al. 1996).

The reversibility of flocculation with the TEMPO CNF was also studied (Fig3). From the Fig3 we can see that the TEMPO CNF showed a significant reflocculation capability. As expected after an increase of the shear (from 500 to $1000 \mathrm{rpm}$ ), the transmission level of the PCC suspension started to decrease, indicating a breakage of flocs. When the mixing speed was lowered back to $500 \mathrm{rpm}$, the transmission level increased significantly, indicating a strong reflocculation of the PCC. After several high shear stages, reflocculation of PCC was still significant, especially at the dosage level of $0.5 \%$ of 


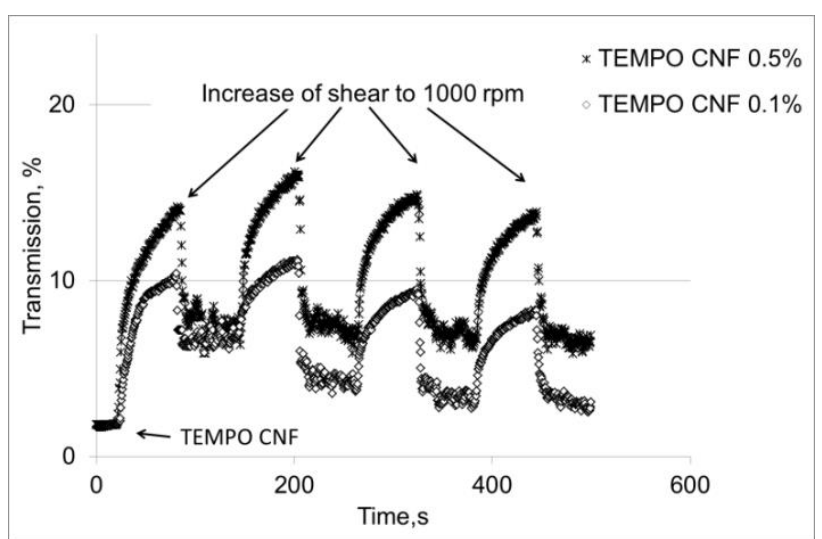

Fig 3 - Flocculation and re-flocculation of PCC with TEMPO CNF at two different dosages (\% of dry weight of PCC) as a function of time. The shear was varied between 500 and 1000 rpm. The consistency of the PCC suspension was $0.1 \%$.

TEMPO CNF. According to the theory presented by Kasper (1971), only patch flocculants show reversible flocculation behavior. By using multi component systems, reversible flocculation can also occur (Hedborg, Lindström 1996). In contrast, the flocculants which function through bridging show usually almost no reflocculation behavior (Deng, Yoon 2004; Rasterio 2008; Rasteri et al. 2008). This was also seen in our studies, as APAMs did not show any re-flocculation behavior (results not shown). The structure of CNF is different than the common bridging flocculants such as linear PAMs. The conformation of common bridging flocculants changes significantly as a function of time or if they are exposed under high shear. They usually flatten on the surfaces and therefore almost no reflocculation occurs (Hedborg, Lindström 1996). In contrast, CNF fibrils are stiffer and form an inter-linked network already in very dilute aqueous suspensions (Salmi et al. 2009). Therefore, high shear might not have a significant influence on their conformation at the surface. A similar effect has also been seen for highly cross-linked polyelectrolytes by Hedborg and Lindström (1996). They suggested that for these types of polyelectrolytes the flocculation mechanism is a hybrid between patch and bridging flocculation, which provides better reversibility of flocculation. This explanation seems reasonable also for CNFs. CNF fibrils have a large specific surface area and a high aspect ratio meaning that they can flocculate PCC particles mainly through bridging/ networking. After the high shear is applied and flocs break, extended CNF patches on the flocs could approach adjacent flocs, leading to reflocculation of PCC through patch or networking mechanisms.

The flocculation of anionic kaolin particles was studied with two cationic CNFs, one with a low degree of substitution $(0.4 \mathrm{meq} / \mathrm{g})$ and one with a high degree of substitution (1.4 meq/g). Similar to PCC, kaolin can be effectively flocculated by oppositely charged CNF. In addition, the flocculation of kaolin particles occurred very fast (to a maximum at 15 to 20 seconds) after the
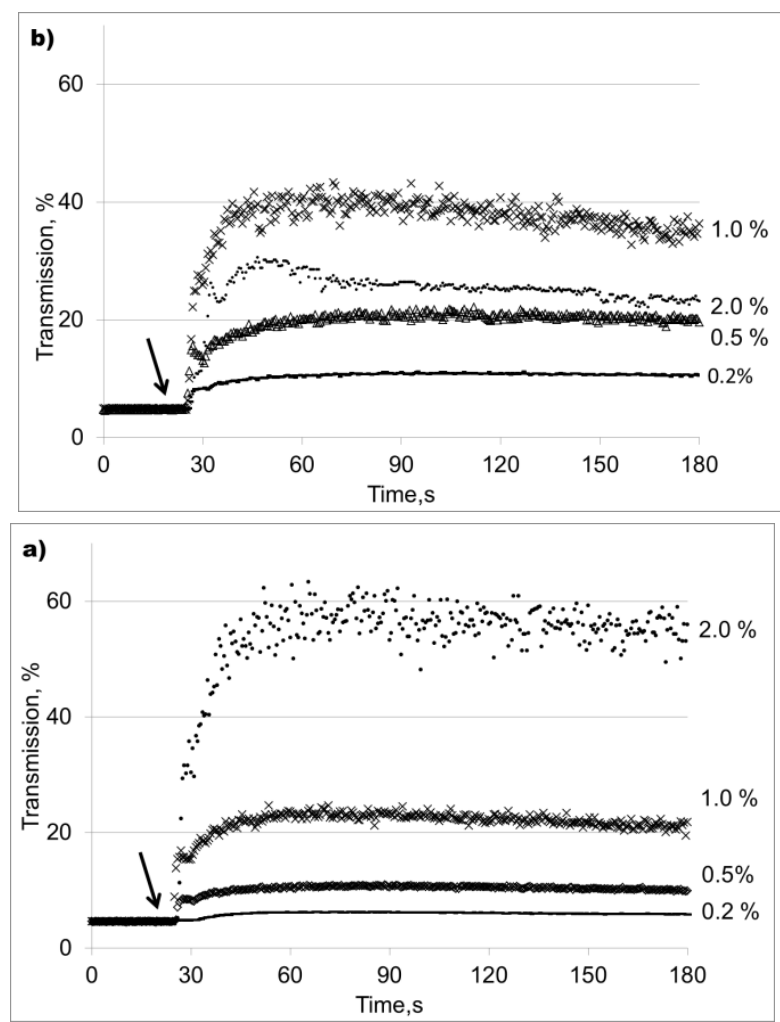

Fig $4 \mathrm{a}$ and $4 \mathrm{~b}$ - Flocculation of kaolin with low CD CNF (0.41 $\mathrm{meq} / \mathrm{g})(\mathrm{a})$ and high CD CNF (1.37 meq/g) (b). The dosage start time (20s) is shown by arrow. The consistency of the kaolin suspension was $0.1 \%$.

addition of cationic CNF (Fig $4 a$ and $4 b$ ). With low charge density (CD) cationic CNF, flocculation is inefficient at low dosages $(0.2-0.5 \%)$ (Fig 5). However, as the dosage increased the flocculation efficiency increased significantly. With an addition level of $2.0 \%$ a transmission level as high as $60 \%$ was achieved, indicating very substantial flocculation of kaolin (the absolute values between PCC and kaolin can not be compared due to different particle properties). With higher $\mathrm{CD}$ cationic CNF, flocculation is significantly higher at lower dosages. However, the maximum flocculation is achieved already at an addition level of $1.0 \%$ of CNF and it is clearly lower (40\%) than with low $\mathrm{CD} \mathrm{CNF}$. Above the dosage of maximum flocculation, the degree of flocculation starts to decrease, probably due to electrostatic/ electrosteric repulsion between kaolin particles covered with cationic CNF (Swerin et al. 1996). This is similar to the effect that was seen with anionic CNFs and PCC, supporting the idea that the basic flocculation mechanisms are the same for anionic and cationic CNF.

\section{Flocculation of fillers with two component systems}

Multicomponent flocculation and retention systems are commonly used in papermaking mainly due to their betterefficiency compared to single component systems (Hedborg, Lindström 1996; Nyström et al. 2003a, 2003b; Petzold et al. 2003; Deng, Yoon 2004). Therefore, our 


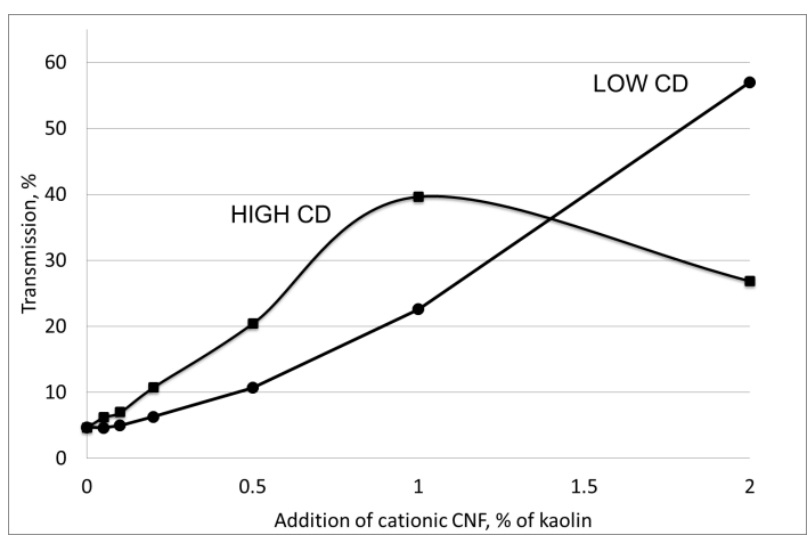

Fig 5 - Flocculation of kaolin with cationic CNFs with two different DS (60 s after addition of CNF). The consistency of the kaolin suspension was $0.1 \%$.

interest was also to study if flocculation efficiency could be improved by combining $\mathrm{CNF}$ with polyelectrolytes. The sequential addition of CNF and polyelectrolytes has been found to be more efficient in several paper chemistry applications than pre-mixing (Ahola et al. 2008a). Accordingly, a sequential addition strategy was chosen.

When cationic PCC particles were flocculated, the anionic CNF was always added first, followed by addition of a cationic polyelectrolyte. After CNF addition the sample was mixed for 60 seconds, after which the cationic polyelectrolyte was added. Fig $6 a$ and $6 b$ presents a flocculation measurement with a two component system, where TEMPO CNF and cationic, high molecular weight CPAM were sequentially added to the PCC suspension (additions at $20 \mathrm{~s}$ and $80 \mathrm{~s}$, respectively). In Fig $6 a$, the addition of the TEMPO CNF was fixed at $0.1 \%$, while dosing of the CPAM varied from $0.025 \%$ to $0.5 \%$. After the addition of $0.1 \%$ anionic TEMPO CNF, a relative slow maximum flocculation of cationic PCC particles was obtained (as in Fig 2a, one component system). Thereafter, the addition of CPAM led to a rapid flocculation of PCC. The highest values of the transmission were somewhere above $25 \%$, which was significantly higher than with TEMPO CNF alone. The most efficient flocculation was achieved already at $0.025 \%$ CPAM addition. This indicates that the number of free anionic surface sites for the adsorption of cationic polymer was relative low. Indeed, the dosing of TEMPO CNF was quite low (only $0.1 \%$ ), if you compare it to the optimal one component TEMPO CNF flocculation concentration (somewhere between 0.5 and $1.0 \%$, Fig 2a). When the dosing of the TEMPO CNF was increased to $0.5 \%$, the flocculation of PCC was significantly enhanced (Fig $6 b$ ). A transmission level as high as $60 \%$ was observed. The initial flocculation was faster, and more efficient (as in Fig 2a) with the TEMPO CNF (increase of transmission from $10 \%$ to about $15 \%$ ), but especially when the CPAM was added to the PCC suspension, one can see a drastic increase in the
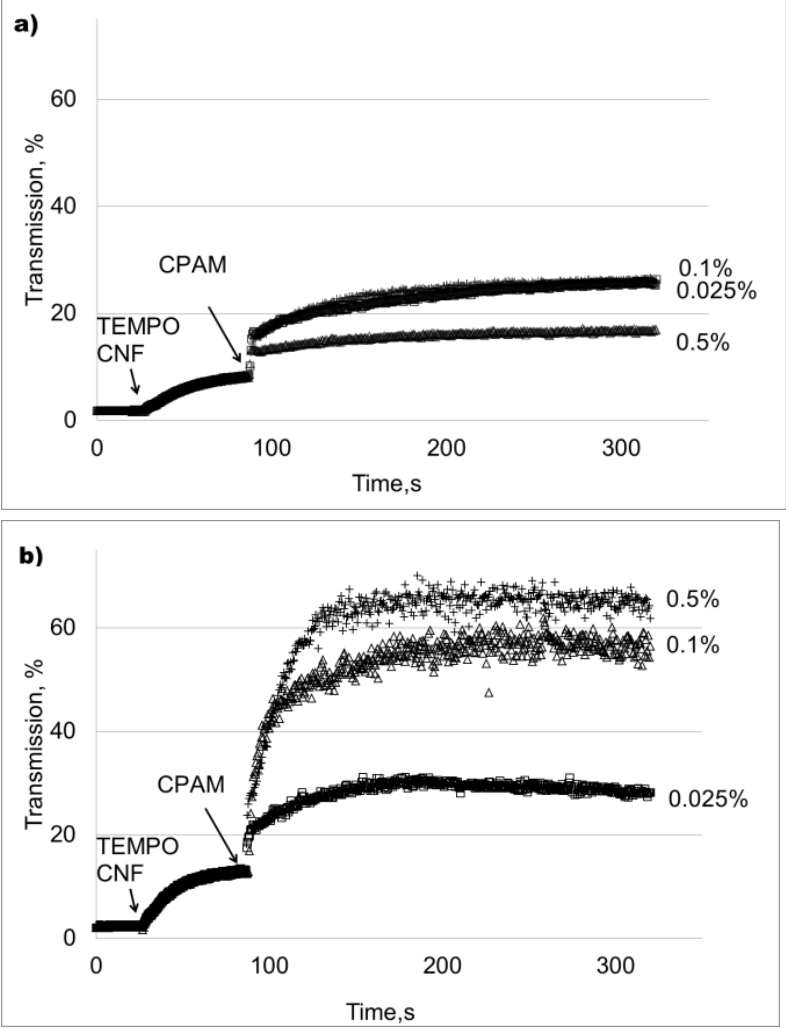

Fig $6 \mathrm{a}$ and $6 \mathrm{~b}$ - Flocculation of PCC with TEMPO CNF dosages of $0.1 \%$ (a) and $0.5 \%$ (b) and CPAM (three addition levels $0.025,0.1$ and $0.5 \%$ ). Dosages of TEMPO CNF and CPAM are given as \% of dry weight of PCC. The consistency of the PCC suspension was $0.1 \%$.

transmission level, indicating very strong flocculation of the PCC. The highest flocculation was achieved at a high addition level of CPAM $(0.5 \%)$. This indicates that in a two component anionic $\mathrm{CNF} /$ cationic polymer system, efficient flocculation is obtained when a high enough number of anionic sites from TEMPO CNF is present which the cationic polymer can attach to (Nyström et al. 2003a).

Fig 7 summarizes the flocculation of PCC with the TEMPO CNF/CPAM systems (total contact time 120s). In order to compare the efficiency of one and two components systems, one component APAM (the most efficient system in Fig 1) was used as a reference for the two component systems. The CPAM that was used in the TEMPO CNF/ CPAM systems had about the same molecular weight (ca. $7 \mathrm{mil} . \mathrm{g} / \mathrm{mol}$ ) as the APAM. With two component systems one can get significantly higher flocculation levels than with single component APAM. The high flocculation efficiency of the two component system is probably because the CPAM can efficiently attach to the previously formed anionically charged PCC aggregates (covered with TEMPO CNF) and form even larger aggregates. Another reason for the efficient flocculation could also be free TEMPO CNF fibrils in the suspension which form complexes with the CPAM, 


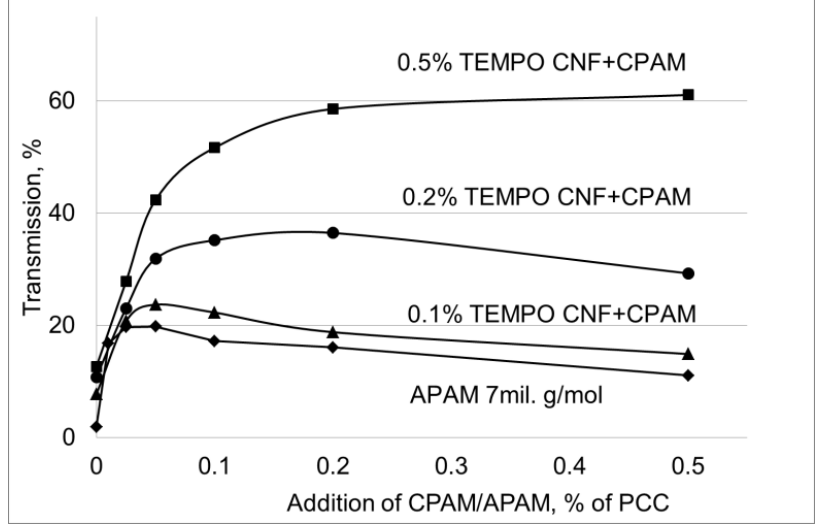

Fig 7 - Flocculation of PCC with the two component system of TEMPO CNF and CPAM after TEMPO CNF and CPAM addition (total contact time $120 \mathrm{~s}$ ). Three addition levels of TEMPO CNF $(0.1,0.2$ and $0.5 \%)$ and five different addition levels of CPAM were used (TEMPO CNF and CPAM are given as $\%$ of dry weight of PCC). APAM (CD -1.6 meq $/ \mathrm{g}, \mathrm{Mw} 7 \mathrm{mil} . \mathrm{g} / \mathrm{mol}$ ) was used as a reference. The consistency of the PCC suspension was $0.1 \%$.

further increasing the flocculation efficiency. Salmi et al. (2009) found in their surface force experiments that CNFs and a high molecular weight CPAM can form an extremely thick, loose and viscoelastic layer. This supports the idea of the ability of CNF to form long-range networks with polyelectrolytes, thus causing an efficient two component flocculation.

Flocculation of kaolin was also studied with a two component system (Fig 8). As kaolin has a net anionic charge, a cationic polyelectrolyte (PEI in this case) was first added to kaolin suspension, and after $60 \mathrm{~s}$ mixing anionic TEMPO CNF was introduced to the system. PEI is a common retention aid which flocculates particles mainly through the patching mechanism (in one component systems) (Roberts, 1996). It has a very high charge density and therefore its efficient flocculation concentration range is very narrow. Alone it is not a very efficient flocculant, and therefore it is usually used in combination with bridging flocculants such as APAM (Hedborg, Lindström 1996; Deng, Yoon 2004). Here, the idea was that TEMPO CNF acts as bridging flocculant in the two component system (PEI + TEMPO CNF), replacing APAM.

Similarly, as in the flocculation of PCC, the flocculation of kaolin enhanced when using the two component system (PEI and TEMPO CNF, Fig, 8). Wågberg et al. (2008) noticed in their model surfaces studies that PEI and CNFs form very thick multilayers. This is mainly due to the conformation and branched structure of PEI. The long range PEI/ TEMPO CNF networks will probably increase the interaction between the surfaces of adjacent kaolin particles, leading to a high degree of flocculation for kaolin. The flocculation efficiency of the PEI/TEMPO CNF system depends strongly on the dosage of the PEI (Fig 8). At the low addition level of PEI $(0.1 \%)$, the

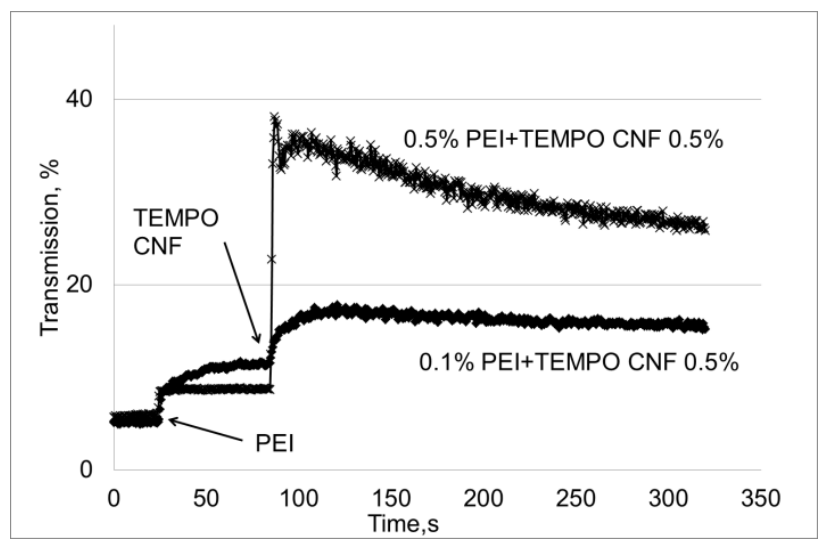

Fig 8 - Flocculation of kaolin with PEI+TEMPO CNF system. Dosages of TEMPO CNF and PEI are given as \% of dry weight of kaolin. The consistency of the kaolin suspension was $0.1 \%$.

addition of TEMPO CNF only slightly increased the flocculation of kaolin (from $10 \%$ to $17 \%$ ). As the PEI dosage was increased to $0.5 \%$, which was clearly an overdosage (because initial flocculation was lower than with the $0.1 \%$ dosage), the flocculation of kaolin with TEMPO CNF was significantly boosted (transmission level increases over 30\%). This indicates that a high number of free cationic sites have to be present on the kaolin surface (charge reversal with PEI), in which TEMPO CNF could attach, and form an extended bridging/ network for efficient flocculation. The other flocculation mechanisms could be that, in the presence of free polycations (excess of PEI), the cationic polyelectrolytes and anionic CNFs form complexes, and act similarly as traditional network flocculants such as PEO and cofactors (Xiao et al. 1996).

These results clearly show that CNFs can be used as effective flocculants. However, CNFs should be chemically modified (add charged groups) in order to increase their electrostatic interactions with particles and with other additives in the system. Charge modified CNFs seem to work as single flocculants but the efficiency is significantly improved when they are combined with polyelectrolytes. It is probable that CNF with its high surface area forms networks between particles, and polyelectrolytes can form bridges between these networks, leading to efficient flocculation.

\section{Retention of kaolin with different CNFs}

As the flocculation experiments showed, different CNF grades can flocculate filler particles. Therefore, it was of interest to see if they can also increase the retention of fillers in the papermaking furnish. The experiments were made with the Dynamic Drainage Jar (DDJ) with a furnish containing TMP (60 w-\%) and kaolin (40 w- $\%$ ). As both TMP and kaolin have an anionic surface charge, the retention of kaolin was studied with the two cationic CNFs (high $\mathrm{CD}$ and low CD). In addition, a two component system, PEI + TEMPO CNF), was also studied. 


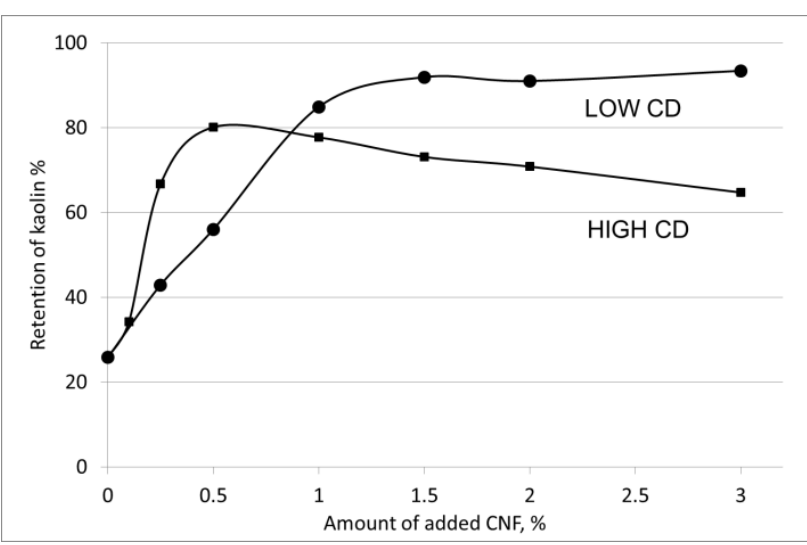

Fig 9 - Retention of kaolin in the wire as a function of cationic CNFs addition. The furnish contained TMP (60 w- $\%)$ and kaolin (40 w-\%).

The retention of kaolin filler can clearly be affected by the addition of cationic CNFs (Fig 9). This is a result of the aggregation of kaolin particles into larger aggregates by CNFs, which can then be retained on the wire (Guimond et al. 2010; Ämmälä et al. 2013). With the high CD cationic CNF, retention starts to increase already at low CNF dosage levels (0.025\%); the highest retention is achieved at $0.5 \% \mathrm{CNF}$ dosage. After the maximum, the retention starts to deteriorate, probably due to a decrease in the optimum bridging and charge conditions (Swerin et al. 1996). The retention efficiency of CNF depends on its charge density. With the low CD cationic CNF, the dosage has to be significantly higher than that of high CD CNF in order to achieve a high retention of kaolin (Fig 9). However, one can achieve a significantly higher maximum retention with the low $\mathrm{CD}$ cationic $\mathrm{CNF}$. With the high $\mathrm{CD} C \mathrm{CNF}$ the maximum retention was about $80 \%$, while it was above $95 \%$ with the low CD CNF. In addition, one can use a wide concentration range of low $\mathrm{CD} \mathrm{CNF}$ and still achieve maximum retention of kaolin. All these observations are consistent with those seen in the flocculation experiments with kaolin (Fig 5). It seems that in the case of one component high CD CNF, the flocculation and retention behavior resembles that of patch flocculants (sensitive to charge); while for the low $\mathrm{CD}$ CNF other mechanisms, such as bridging, are more probable.

A two component system was also tested (Fig 10). Here, the idea was similar to the flocculation tests; TEMPO CNF (in PEI + TEMPO CNF system) replaces the commonly used bridging flocculant, APAM, in the two component system (PEI + APAM) (Hedborg and Lindström 1996). First, highly surface charge cationic polyelectrolyte (PEI) was added and, after that, anionic TEMPO CNF. Similarly as in the flocculation experiments, enough cationic charge must be present in the system. With the low addition level of PEI $(0.025 \%)$ retention of kaolin is very low. This indicates that there are not enough free cationic spots present on the furnish

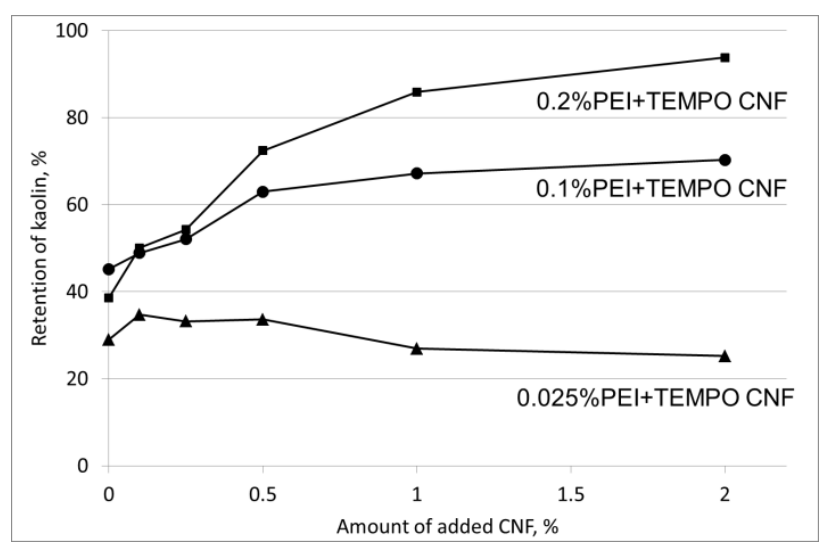

Fig 10 - Retention of kaolin in the wire as a function of added PEI and TEMPO CNF. The consistency of the furnish was $0.5 \%$ and it consisted of TMP (60 w- $\%)$ and kaolin (40 w- $\%$ ).

in which the TEMPO CNF could attach and bind the kaolin flocs to the sheet in the wire. Similar observations have been made by Suopajärvi et al. (2013) in waste water treatment. They used a cationic ferric coagulant $\left(\mathrm{Fe}_{2}(\mathrm{SO})_{4}\right.$ in a combination with anionic CNF. They observed that, in general, an addition of a cationic component was crucial for flocculation of wastewater. Furthermore, its optimal dosing was very important to gain an efficient flocculation with anionic CNF. Similarly, in our experiments, as the dosing of the PEI is increased, the retention of kaolin also increases significantly. With $0.2 \%$ PEI addition and 2\% TEMPO $\mathrm{CNF}$, retention levels as high as $95 \%$ can be achieved. These results are consistent with the observations made in the flocculation tests with the PEI+TEMPO CNF systems (Fig 8).

\section{Conclusions}

These results clearly show that different CNFs can be used as effective flocculants. However, CNFs have to be chemically modified (high number of charged groups) in order to increase their electrostatic interactions with particles and other additives in the system. Hence, unmodified CNF, which has a low charge density, does not show any flocculation capability. When CNF contains more charged groups, either by carboxymethylation or by TEMPO-oxidation, the flocculation efficiency of cationic PCC particles is significantly improved. A similar effect was found with cationically modified CNFs that flocculated negatively charged kaolin particles effectively. The charge density of CNF had also impact on the flocculation kinetics. The high charge CNF had faster flocculation kinetics than low charge CNF. One component CNF systems also showed a significant reflocculation tendency, which is unusual for polymeric single flocculant systems. This indicates that the flocculation mechanism for CNFs is not only bridging but more of a hybrid between bridging/networking and the patch flocculation mechanisms. The flocculation efficiency was significantly improved when charge 
modified CNFs were combined with polyelectrolytes. The presence of polyelectrolytes can strengthen and induce formation of $\mathrm{CNF} /$ polyelectrolyte bridges between filler particles, leading to efficient flocculation. Similar observations were made in retention experiments. Hence, charge modified CNF could be used to increase the retention of filler up to $95 \%$ in both one and two component systems.

\begin{tabular}{l}
\hline Acknowledgements \\
UPM-Kymmene Ltd, Finland is acknowledged for financial \\
support. Finnish Centre for Nanocellulosic Technologies, \\
Sigma-Aldrich St. Louis, MO, USA, Kemira Ltd, Finland and \\
UPM-Kymmene Ltd, Finland are acknowledged for contributing \\
the samples.
\end{tabular}
the samples.

\section{Literature}

Ahola, S. Österberg, M. Laine, J. (2008a): Cellulose nanofibrils-adsorption with poly(amideamine)epichlorohydrin studied by QCM-D and application as a paper strength additive, Cellulose, 15(2), 303-314

Ahola, S. Salmi, J. Johansson, L.S. Laine, J. Österberg, M. (2008b): Model films from native cellulose nanofibrils. Preparation, swelling, and surface interactions, Biomacromolecules, 9(4), 1273-1282

Aly, A.A. (2006) : Preparation, characterization and evaluation of anionic starch derivatives as flocculants and for metal removal, starch, 58(8), 391-400

Biswal, D.R. Singh, R.P. (2004): Characterisation of carboxymethyl cellulose and polyacrylamide graft copolymer, Carbohydr. Polym., 57(4), 379-387

Biswal, D.R. Singh, R.P. (2006) : Flocculation studies based on water-soluble polymers of grafted carboxymethyl cellulose and polyacrylamide, J. Appl. Polym. Sci., 102(2), 1000-1007

Bordes, C. Garcia, F. Snabre, P. Frances, C. (2002): On-line characterization of particle size during an ultrafine wet grinding process, Powder Technology, 128(2-3), 218-228

Bragd, P.L. van Bekkum, H. Besemer, A.C. (2004) : TEMPOmediated oxidation of polysaccharides:survey of methods and applications, Top catal., 27, 49-66

Britt, K.W. Unbehend, J.E. (1976) : New method of monitoring retention, Tappi, 59(2), 67-70

Chen, Y. Liu, S. Wang, G. (2007): Flocculation properties and adsorption kinetics of cationic starches in kaolin suspensions, J. Appl. Polym. Sci., 105(2), 2841-2849

Deng, Y. Yoon, S.Y. (2004) : Flocculation and reflocculation of clay suspension by different polymer systems under turbulent conditions, J. Colloid Interface Sci., 278(1), 139-145

Dimic-Misic, K. Gane, P. A. C. and Paltakari, J. (2013): Micro- and nanofibrillated cellulose as a rheology modifier additive in CMC-containing pigment-coating formulations, Ind. Eng. Chem. Res., 52(45), 16066-16083

Eriksen, Ø. Syverud, K. Gregersen, Ø. (2008) : The use of microfibrillated cellulose produced from kraft pulp as strength enhancer in TMP paper, Nord. Pulp Pap Res. J., 23(3), 299-304
Eronen, P. Laine, J. Ruokolainen, J. Österberg, M. (2012) : Comparison of multilayer formation between different cellulose nanofibrils and cationic polymers J. Colloid Interface Sci., 373(1), 84-93

Fang, R. Cheng, X. Xu, X. (2010) : Synthesis of lignin-base cationic flocculant and its application in removing anionic azodyes from simulated wastewater, Bioresour. Technol., 101(19), 7323-7329

Fleer, G.J. Cohen Stuart, M.A. Scheutjens, J.M. Cosgrove, T. Vincent, B. (1993) : Polymers at interfaces, Chapman\&Hall, University Press, Cambridge, UK, 502p.

Ghimici, L. Nichifor, M. (2010): Novel biodegradable flocculanting agents based on cationic amphiphilic polysaccharides, Bioresour. Technol., 101(22), 8549-8554

Guimond, R. Chabot, B. Law, K-N. Daneault, C. (2010): The use of cellulose nanofibres in papermaking, J. Pulp Pap. Sci., 36(1-2), 3655-3661

Henriksson, M. Berglund, L. Isaksson, P. Lindström, T. Nishino, T. (2008): Cellulose nanopaper structures of high toughness, Biomacromolecules, 9(6), 1579-1585

Hedborg, F. Lindström, T. (1996) : Some aspects on the reversibility of flocculation of paper stocks, Nord. Pulp Pap Res. J., 11(4), 254-259

Hubbe, M. Rojas, O.J. Lucia, L.A. Sain, M. (2008) : Cellulosic nanocomposites: A review, BioResources, 3(3), 929-980

Isogai, A. Saito, T. Fukuzumi, H. (2011): TEMPO-oxidized cellulose nanofibers, Nanoscale, 3, 71-85

Junka, K. Filpponen, I. Lindström, T. Laine, J. (2013): Titrimetric methods for the determination of surface and total charge of functionalized nanofibrillated/microfibrillated cellulose (NFC/MFC), Cellulose, 20(6), 2887-2895,

Kasper, D. (1971) : Theoretical and experimental investigations of the flocculation of charged particles in aqueous solutions by polyelectrolytes of Opposite Charge, Ph.D. thesis, California Institute of Technology

Koljonen, K. Mustaranta, A. Stenius, P. (2004): Surface characterisation of mechanical pulps by polyelectrolyte adsorption, Nord. Pulp Pap Res. J., 19(4), 495-505

Korhonen, M.H.J. Holappa, S. Stenius, P. Laine, J. (2013) : Flocculation of fillers with polyelectrolyte complexes, Nord. Pulp Pap Res. J., 28(2), 239-247

Liimatainen, H. Sirviö, J. Sundman, O. Visanko, M. Hormi, O. Niinimäki, J. (2011) : Flocculation performance of a cationic biopolymer derived from a cellulosic source in mild aqueous solution, Bioresour. Technol., 102(20), 9626-9632

Nyström, R. Rosenholm, J.B. Nurmi, K. (2003a): The effect of pretreatment of calcite dispersions with anionic sodium polyacrylate on their flocculation behavior induced by cationic starch, J.Colloid Interface Sci., 262(1), 48-54

Nyström, R. Backfolk, K.. Rosenholm, J.B. Nurmi, K. (2003b): Flocculation of Semidilute Calcite Dispersions Induced by Anionic Sodium Polyacrylate-Cationic Starch Complexes, Langmuir, 19(9), 3981-3986 
Olszewska, A. Eronen, P. Johansson, L.-S. Alho, H.-M. Ankerfors, M. Lindström, T. Ruokolainen, J. Laine, J. Österberg, M. (2011) : The behaviour of cationic nanoFibrillar cellulose in aqueous media. Cellulose, 18(5), 1213-1226

Petzold, G. Schwarz, S. Lunkwitz, K. (2003): Higher efficiency in particle flocculation by using combinations of oppositely charged polyelectrolytes, Chem. Eng. Technol., 26, 48-53

Pääkkö, M. Ankerfors, M. Kosonen, H. Nykänen, A. Ahola, S. Österberg, M. Ruokolainen, J. Laine, J. Larsson, P.T. Ikkala, O. Lindström, T. (2007) : Enzymatic hydrolysis combined with mechanical shearing and high-pressure homogenization for nanoscale cellulose fibrils and strong Gels, Biomacromolecules, 8(6), 1934-1941

Rasteiro, M. (2008): Evaluation of flocs resistance and reflocculation capacity using the LDS technique, Powder Technology, 183(2), 231-238

Rasteiro, M. Antunes, E. Garcia, F.A.P. Ferreira, P. Blanco, A. Negro, C. (2008) : Effect of water cationic content on flocculation, flocs resistance and reflocculation capacity of PCC induced by polyelectrolytes, Ind. Eng. Chem. Res. 47(16), 6006-6013

Roberts, J.C.(ed.) (1996): The chemistry of paper, Royal Society of Chemistry, Cambridge, UK, 64-82

Saito, T. Kimura S. Nishiyama, Y. Isogai, A. (2007): Cellulose nanofibers prepared by TEMPO-mediated oxidation of native cellulose Biomacromolecules, 8(8), 2485-2491

Salmi, J. Nypelö, T. Österberg, M. Laine, J. (2009) : Layer structures formed by silica nanoparticles and cellulose nanofibrils with cationic polyacrylamide (C-PAM) on cellulose surface and their influence on interactions, Bioresources, 4(2), 602-625

Shirzad-Semsar, M. Scholz, S. Kulicke, W-M. (2007): Cationic starches as substitute for synthetic cationic flocculants in solid-liquid separation of harbor sludge, J. Phys.Chem B, 111(29), 8641-8648

Sirviö, J. Hyväkkö, U. Liimatainen, H. Niinimäki, J. Hormi, O. (2011a): Periodate oxidation of cellulose at elevated temperatures using metal salts as cellulose activators, Carbohydr. Polym., 83(3), 1293-1297

Sirviö, J. Honka, A. Liimatainen, H. Niinimäki, J. Hormi, 0. (2011b) : Synthesis of highly cationic water-soluble cellulose derivative and its potential as novel biopolymeric flocculation agent, Carbohydr. Polym., 86(1), 266-270

Sjöström, E. (1993): Wood Chemistry, fundamentals an applications, second ed., Academic Press, San Diego, USA

Suopajärvi, T. Liimatainen, H. Hormi, O. Niinimäki, J. (2013): Coagulation-flocculation treatment of municipal wastewater based anionized nanocelluloses, Chem. Eng. J., 231, 59-67

Swerin, A. Ödberg, L. Wågberg, L. (1996): An extended model for the estimation of flocculation efficiency factors in multicomponent flocculant systems, Colloids Surf., A, 113(1-2), 25-38
Taipale, T. Österberg, M. Nykänen, A. Ruokolainen, J. Laine, J. (2010) : Effect of microfibrillated cellulose and fines on the drainage of kraft pulp suspension and paper strength, Cellulose, 17(5), 1005-1020

Walecka, J.A. (1956): An investigation of low degree of substitution of carboxymethylcelluloses, Tappi J, 39(7), 458-463

Wei, Y. Cheng, F. Zheng, H. (2008): Synthesis and flocculating properties of cationic starch derivatives, Carbohydr. Polym., 74(3), 673-679

Wågberg, L. Decher, G. Norgren, M. Lindström, T.Ankerfors, M. Axnäs, K. (2008): The build-Up of polyelectrolyte multilayers of microfibrillated cellulose and cationic polyelectrolytes, Langmuir, 24(3), 784-795

Yokoi, H. Obita, T. Hirose, J. Hayashi, S. Takasaki Y. (2002): Flocculation properties of pectin in various suspensions, Bioresour. Technol., 84(3), 287-290

Xiao, H. Pelton, R. Hamielec, A. (1996): Retention mechanisms for two-component systems based on phenolic resins PEO or PEO-copolymer retention aids, J. Pulp Pap. Sci., 22(12), J475-J485

Ämmälä, A. Liimatainen, H. Burmeister, C. Niinimäki, J. (2013): Effect of tempo and periodate-chlorite oxidized nanofibrils on ground calcium carbonate flocculation and retention in sheet forming and on the physical properties of sheets. Cellulose, 20(5), 2451-2460

Manuscript received December 1, 2013 Accepted February 3, 2014 